\title{
The public's risk perception of blood transfusion in Saudi Arabia
}

\section{Adel F Almutairi \\ Mahmoud Salam \\ Oraynab Abou Abbas \\ Maliha Nasim \\ Abdallah A Adlan}

King Abdullah International Medical Research Center, King Saud bin Abdulaziz University for Health Sciences, Ministry of National Guard Health Affairs, Riyadh, Saudi Arabia

Correspondence: Adel F Almutairi Science and Technology Unit, King Abdullah International Medical Research Center, King Saud bin Abdulaziz University of Health Sciences, Ministry of National Guard Health Affairs, P.O Box 22490, Riyadh II426, Saudi Arabia Email almutairiad।@ngha.med.sa
This article was published in the following Dove Press journal:

Journal of Blood Medicine

Background: Human beings may face many circumstances, such as surgery, trauma, and anemia, in which they could require an urgent blood transfusion. However, only a few studies have examined people's risk perception of blood transfusion. Therefore, this study aims to evaluate the public's risk perception of blood transfusion in Saudi Arabia, and to identify factors associated with their risk perception.

Methods: Self-reported questionnaires on blood transfusion risk perception were distributed to the public during a Saudi national festival in Riyadh. Data were analyzed using mean, SD, Student's $t$-test, and linear regression.

Results: The overall percentage mean score \pm SD of risk perception was $59.8 \pm 16.1$. Male participants were significantly more likely to perceive blood transfusion negatively, both in terms of the dread/severity domain $(\beta=-0.23, p=0.003)$ and their overall risk perception score $(\beta=-0.17$, $p=0.028$ ). Older participants were considerably more likely to have a more negative perception ( $\beta=0.12, p=0.041$ ) of the benefits of blood transfusion compared with younger participants. Study participants who received blood in the past had a significantly better perception $(\beta=-0.13$, $p=0.029$ ) of the benefits of transfusion. Additionally, participants who had previously donated blood had a considerably more positive perception in the dread/severity domain $(\beta=-0.18$, $p=0.017)$ and their overall score $(\beta=-0.15, p=0.045)$.

Conclusion: Saudi males are more likely to perceive blood transfusion as a high-risk procedure. Similarly, older Saudis will probably have a more negative perception of the benefits of blood transfusion. Previous recipients and donors will likely have a better perception of the benefits of blood transfusion and a more positive overall risk perception.

Keywords: blood transfusion, perception, risk, knowledge, benefit, Saudi

\section{Introduction}

Blood is a vital fluid in our bodies and is mainly composed of red blood cells (RBCs), white blood cells (WBCs), clotting factors, platelets, and plasma. Each of these components performs important functions. For example, RBCs are responsible for transporting oxygen from the lungs to the billions of cells in the body, and then carrying back carbon dioxide to the lungs to be expelled out of the body. Meanwhile, WBCs are part of the immune system and help detect and defend our bodies against foreign substances and diseases, whereas platelets and clotting factors are responsible for stopping bleeding. As the fluid component of the blood, the plasma helps transport the other components of the blood, nutrients, hormones, electrolytes, and proteins, to the organs and cells throughout the body that need them. Plasma also transports the waste products of the cells to the lungs, kidneys, and digestive system, from which they can be expelled 
from the body. In addition to the functions listed above, the blood serves as a regulatory mechanism for the body's $\mathrm{pH}$ and temperature. Consequently, a deficiency in one or all of these components can be life-threatening.

Human beings can face various situations in which they may require urgent blood for either whole blood or a specific blood component in order to save their lives. Such incidences include, but are not limited to, surgery, serious accidents, civil and military wars, terrorist acts, and earthquake tragedies. Other pathological situations such as anemia or sickle cell anemia, and particular treatment protocols, such as those used in cancer treatment, may require blood transfusion. ${ }^{1}$ Regardless of the ongoing attempts over the last seven decades to develop blood substitutes, ${ }^{2-5}$ human blood donations remain the only source of blood components. ${ }^{6}$

Therefore, maintaining an adequate and safe blood supply in national blood banks should be an integral component of every country's national health care policy, as recommended by the World Health Organization (WHO). ${ }^{7}$ However, this objective is usually challenged by the number of voluntary donations, which may increase and decrease, depending on the season and/or due to an increase in demand. ${ }^{1}$ Another reason for the decline in donations, according to Al-Drees, ${ }^{1}$ is the strictness of the screening guidelines, which may minimize the number of people eligible to donate blood. Many studies conducted in the literature in both developed and developing countries, including Saudi Arabia, have thus examined people's knowledge and attitudes regarding blood donations. ${ }^{1,8-12}$ Most of these studies have attributed the decline in the number of blood donations to insufficient knowledge, misconceptions, lack of time, negative attitudes, and fears of blood donation procedure.

However, a few studies have examined people's risk perceptions of blood transfusions, particularly in Saudi Arabia. This issue has become even more important after a series of incidences related to the transfusion of contaminated blood to patients in Saudi Arabia, in which human immunodeficiency virus (HIV)-infected blood was transmitted to a young Saudi girl in the southern region of Saudi Arabia. ${ }^{8}$ Blood transfusions are generally regarded as a safe procedure due to the strict national and international screening guidelines recommended by the WHO. ${ }^{13}$ This incident as well as the others may have contributed to an increase in anxiety levels among the Saudi public regarding the risks associated with blood transfusions and a reduction in people's level of trust in blood banks. The incident may also give rise to psychological challenges for current and potential blood recipients and their families. Thus, the aim of this study was to evaluate the public's risk perception of blood transfusion in Saudi Arabia.

\section{Materials and methods Population and sampling}

This study targets the public Saudis in Riyadh city. Convenience sampling was used to select the participants for this study. Eligible participants were adult ( $\geq 18$ years of age) Saudi nationals living in Riyadh City who had no mental impairments. The research team approached potential participants at a national festival for heritage and culture that always takes place in Riyadh city every year and lasts for 2 weeks. This important national occasion attracts people from all over the Kingdom of Saudi Arabia and beyond from different socioeconomic levels.

The sample size was calculated using a sample calculation formula. One study reported that $46.6 \%$ of its participants gave a moderate to high response to perceiving blood transfusion as a risk to self or family, ${ }^{14}$ while another study noted that $57 \%$ perceived blood transfusion as risk for blood transmitted diseases. ${ }^{15}$ Assuming an expected self-reported perceived risk of blood transfusion of $57 \%$ among this national festival visitors with a $95 \%$ confidence limit $(z=1.96)$, and a margin of error $5.5 \%$, the estimated sample size for this study is 311. Participants were informed that their participation in the study is anonymous and on a voluntary basis.

\section{Data collection}

\section{Instrument}

Data were collected using a risk perception of blood transfusion scale, which is a subset of a larger risk perception questionnaire, which is a tool composed of a number of hazards. ${ }^{16}$ Risk perception of a blood transfusion scale is rated on a 7-point Likert scale with respect to a group of qualitative characteristics, such as overall riskiness, the extent of worry, dread, the benefits provided, the degree to which the risks are known to those exposed, the degree to which the risks are understood by scientists, the likelihood of fatal consequences, the degree to which exposure to the hazard is voluntary, the amount of control an average person has over the risk, and the extent to which future generations are threatened by the risk. ${ }^{16}$ To better quantify the degree of this risk, the statements were categorized into three domains: the dread and severity of this risk, the knowledge and control of this risk, and the benefit of blood transfusion as perceived by the participants. The responses to the statements were converted to scores, and the percentage mean score (PMS) was determined for each domain. 
The tool underwent a series of tests to ensure its cross cultural validity and reliability for use in an Arabic community. It was translated into Arabic and then back into English, with minimal variations observed. An expert in the social sciences evaluated the statements to ensure the appropriateness of the wording, as well as the readability, clarity, and relevance to the context. Six participants were approached for pilot testing, and their subjective comments were taken into consideration.

\section{Procedure}

The research team approached people in the Janadriyah Festival (The National Festival for Heritage and Culture) and invited them to participate in the study. The purpose, procedure, and benefits of the study were explained to them. For those who have agreed to participate, informed consent and study questionnaire were given to them to be signed and filled out. In order to maintain the anonymity of participants, they were asked to insert the questionnaire into a collection envelop. Ethical clearance and approval to conduct this study were obtained from the Institutional Review Board at the Ministry of National Guard-Health Affairs.

\section{Theory/calculation}

The data were analyzed using the Statistics Package for the Social Sciences for Windows, Version 21. The raw data were processed in accordance with the best practices for raw data management to identify any inaccuracies or incompleteness before statistical analysis. A descriptive analysis was carried out to summarize the sample demographic characteristics. Categorical variables (gender, educational level, age group, blood reception, and blood donation) were reported in terms of frequency and percentage. The PMS of the three domains was presented in arithmetic means and SD. Normality tests, using the skewness coefficient, indicated that the dread/ severity domain, the knowledge/control domain, and the overall score were normally distributed; thus, the Student's $t$-test was used as a test of significance. Whereas, the data in the benefit domain were not normally distributed; thus, a Mann-Whitney test was used as a test of significance. A series of linear regression models was constructed to identify factors significantly associated with each of the three domains and the overall score. The level of significance was set at $p$-value $<0.05$.

\section{Results \\ Sample characteristics}

The sample in this study was composed of 312 eligible study participants, of which $101(32.4 \%)$ were males and
$211(67.6 \%)$ were females. On average, participants were $32.5 \pm 10.7$ years; $152(48.7 \%)$ were $<30$ years and 160 $(51.3 \%)$ were $\geq 30$ years. A little more than half the participants $(n=158,50.6 \%)$ had a university level education. The study data indicated that only $24(7.7 \%)$ of the participants reported "ever" receiving a blood transfusion and 84 (26.9\%) reported "ever" donating blood, as shown in Table 1.

\section{Blood transfusion risk scale analysis}

The PMS for the 10 individual statements ranged from $45.4 \pm 28.2$ to $79.8 \pm 25.2$ as indicated in Table 2 . The overall PMS of the perceived risk was 59.8 \pm 16.1 . The number of participants who reported blood transfusions to be a highrisk process was $101(32.3 \%)$, while $83(26.6 \%)$ were very worried about this risk if they had to receive blood, and 85 $(27.3 \%)$ were extremely afraid of this risk. When questioned if a blood transfusion leads to illness or disease, how likely its consequences are to be fatal, $112(35.9 \%)$ were certain they would be fatal. The dread and severity PMS was the lowest with $57.8 \pm 24.3$. On the other hand, there were 217 $(69.6 \%)$ participants who responded neutrally to the fact that the risks of blood transfusion are known to blood recipients, while $145(46.5 \%)$ believed that the risks of blood transfusion are fully understood by scientists. Neutral responses were observed among $182(58.4 \%)$ participants who thought receiving a blood transfusion to be voluntary. There were 68 $(21.8 \%)$ participants who believed that an average person has no control over the risks of blood transfusion, whereas $46(14.7 \%)$ perceived a complete control over the risks. Of the participants, $73(23.4 \%)$ viewed blood transfusion as a

Table I Study sample's characteristics

\begin{tabular}{ll}
\hline Variables & $\begin{array}{l}\text { Frequency n (\%) } \\
\mathbf{3} \mathbf{2}(\mathbf{1 0 0 . 0})\end{array}$ \\
\hline $\begin{array}{l}\text { Gender } \\
\text { Male }\end{array}$ & $101(32.4)$ \\
Female & $211(67.6)$ \\
Age category (years) & \\
$<30$ & $152(48.7)$ \\
$\geq 30$ & $160(51.3)$ \\
Mean \pm SD & $32.5 \pm 10.7$ \\
Education level & \\
School & $154(49.4)$ \\
University & $158(50.6)$ \\
Received blood & \\
No & $288(92.3)$ \\
Yes & $24(7.7)$ \\
Donated blood & \\
No & $228(73.1)$ \\
Yes & $84(26.9)$ \\
\hline Note:n frequen
\end{tabular}

Note: $n$, frequency. 
Table 2 Frequency distribution of responses to the 10-item risk statements

\begin{tabular}{|c|c|c|c|c|c|c|c|c|c|}
\hline \multirow[b]{2}{*}{ Scale } & \multicolumn{8}{|c|}{ Blood transfusion risk score $\mathrm{n}(\%)$} & $\begin{array}{l}\text { Percentage } \\
\text { mean score } \\
x \pm \text { SD }\end{array}$ \\
\hline & I & 2 & 3 & 4 & 5 & 6 & 7 & & \\
\hline $\mathrm{I}$ & \multicolumn{9}{|c|}{ How risky is receiving a blood transfusion? } \\
\hline Not risky & $27(8.7)$ & $16(5.1)$ & $33(10.6)$ & $67(21.5)$ & $68(21.8)$ & $4 I(13.1)$ & $60(19.2)$ & Extremely risky & $59.8 \pm 29.9$ \\
\hline 2 & \multicolumn{9}{|c|}{$\begin{array}{l}\text { If you were to receive a blood transfusion, how worried would you be about the } \\
\text { risk? }\end{array}$} \\
\hline Not worried & $24(7.7)$ & $33(10.6)$ & $55(17.6)$ & $71(22.8)$ & $46(14.7)$ & $19(6.1)$ & $64(20.5)$ & Extremely worried & $54.4 \pm 31.0$ \\
\hline 3 & \multicolumn{9}{|c|}{ Is this a risk that you dread, on a gut level? } \\
\hline Not dreaded & $35(11.2)$ & $34(10.9)$ & $55(17.6)$ & $65(20.8)$ & $38(12.2)$ & $23(7.4)$ & $62(19.9)$ & Extremely dreaded & $52.2 \pm 32.6$ \\
\hline 4 & \multicolumn{9}{|c|}{ To what degree does blood transfusion provide important benefits? } \\
\hline Little or no benefit & II (3.5) & $8(2.6)$ & $17(5.4)$ & $49(15.7)$ & $54(17.3)$ & $50(16.0)$ & $123(39.4)$ & Important benefits & $74.4 \pm 27.4$ \\
\hline 5 & \multicolumn{9}{|c|}{$\begin{array}{l}\text { To what extent are the risks of blood transfusion known to people who received } \\
\text { blood transfusion? }\end{array}$} \\
\hline Risks not known & $19(6.1)$ & $16(5.1)$ & $58(18.6)$ & $102(32.7)$ & $57(18.3)$ & $17(5.4)$ & $43(13.8)$ & Risks well known & $53.9 \pm 26.5$ \\
\hline 6 & \multicolumn{9}{|c|}{ To what extent are the risks of blood transfusion understood by scientists? } \\
\hline Risks not understood & $7(2.2)$ & $6(1.9)$ & $16(5.1)$ & $30(9.6)$ & $44(14.1)$ & $64(20.5)$ & $145(46.5)$ & Risks understood & $79.8 \pm 25.2$ \\
\hline 7 & \multicolumn{9}{|c|}{$\begin{array}{l}\text { If a blood transfusion leads to illness or disease, how likely are the consequences to } \\
\text { be fatal? }\end{array}$} \\
\hline Will not be fatal & $14(4.5)$ & $8(2.6)$ & $32(10.3)$ & $77(24.7)$ & $69(22.1)$ & $43(13.8)$ & $69(22.1)$ & Certain to be fatal & $64.5 \pm 27.0$ \\
\hline 8 & \multicolumn{9}{|c|}{ To what extent is receiving a blood transfusion voluntary? } \\
\hline Involuntary & $35(11.2)$ & $21(6.7)$ & $38(12.2)$ & $83(26.6)$ & $61(19.6)$ & $21(6.7)$ & $53(17.0)$ & Voluntary & $54.1 \pm 30.5$ \\
\hline 9 & \multicolumn{9}{|c|}{ How much control does an average person have over the risk? } \\
\hline No control at all & $43(13.8)$ & $25(8.0)$ & $62(19.9)$ & $102(32.7)$ & $34(10.9)$ & $17(5.4)$ & $29(9.3)$ & Complete control & $45.4 \pm 28.2$ \\
\hline 10 & \multicolumn{9}{|c|}{ To what extent are future generations threatened by this risk? } \\
\hline Not threatened & $25(8.0)$ & $14(4.5)$ & $45(14.4)$ & $88(28.2)$ & $67(21.5)$ & $27(8.7)$ & $46(14.7)$ & Seriously threatened & $55.9 \pm 28.0$ \\
\hline
\end{tabular}

serious threat to future generations. The PMS of the knowledge/control domain was 58.3 \pm 18.2 . Finally, 173 (45.4\%) participants believed that blood transfusions have important benefits, with a PMS for the benefit domain of $59.8 \pm 16.1$.

\section{Factors associated with blood transfusion risks}

Initial bivariate analyses showed that male participants (PMS=77.2 \pm 31.2 ) were more likely to negatively perceive blood transfusion as a beneficial procedure compared with female participants (PMS=73.1 \pm 25.4 ). It also showed that older participants were more likely to have a more negative perception of blood transfusion on the dread/severity domain (PMS=49.4 \pm 29.3 ), the knowledge/control domain

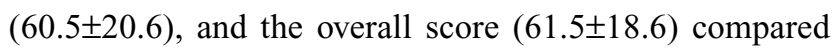
with the younger participants $(54.1 \pm 22.7,56.2 \pm 15.2$, and $57.5 \pm 12.9$, respectively). Table 3 provides details on the comparative analysis of the blood transfusion risk scale and sample demographics.

A series of linear regression models were constructed by adjusting for each of three risk domains and controlling for all possible confounders to identify factors significantly associated with each domain. Male participants were indeed significantly more likely to negatively perceive blood transfusion on the dread/severity domain $(\beta=-0.23, p=0.003)$ and the overall risk perception score $(\beta=-0.17, p=0.028)$ compared with female study participants. Older participants were significantly more likely to have a more negative perception ( $\beta=0.12, p=0.041$ ) toward the benefits of blood transfusion compared with younger participants.

Study participants who received blood in the past had a significantly better perception $(\beta=-0.13, p=0.029)$ toward the benefits of blood transfusion compared with those who did not. Finally, study participants who have donated blood in the past had a significantly more positive perception on the dread/severity domain $(\beta=-0.18, p=0.017)$ and overall score $(\beta=-0.15, p=0.045)$ compared with those who actually donated blood in the past. No significantly associated factors were observed on the knowledge/control domain. Table 4 illustrates in detail the factors significantly associated with the risk of blood transfusion domains.

\section{Discussion}

The findings of our study indicated that $32.3 \%$ of the participants perceived blood transfusions as a high-risk process; a perception that was congruent with the findings of other 
Table 3 The perceived risks of blood transfusion domains across the sample characteristics

\begin{tabular}{|c|c|c|c|c|}
\hline \multirow[t]{2}{*}{ Items } & $\begin{array}{l}\text { Dread and severity, } \\
x \pm \text { SD }\end{array}$ & $\begin{array}{l}\text { Knowledge and } \\
\text { control, } x \pm S D\end{array}$ & Benefit, $x \pm$ SD & Overall, $x \pm$ SD \\
\hline & $57.8 \pm 24.3$ & $58.3 \pm 18.2$ & $74.4 \pm 27.4$ & $59.8 \pm 16.1$ \\
\hline \multicolumn{5}{|l|}{ Gender } \\
\hline Male & $61.9 \pm 30.0$ & $57.5 \pm 22.8$ & $77.2 \pm 31.2$ & $61.0 \pm 20.6$ \\
\hline \multirow[t]{2}{*}{ Female } & $55.8 \pm 21.0$ & $58.7 \pm 15.5$ & $73.1 \pm 25.4$ & $58.7 \pm 13.4$ \\
\hline & $t=1.84, p=0.068$ & $t=-0.47, p=0.638$ & $z=-2.42, p=0.015^{*}$ & $t=1.005, p=0.316$ \\
\hline \multicolumn{5}{|c|}{ Age category (years) } \\
\hline$<30$ & $54.1 \pm 22.7$ & $56.2 \pm 15.2$ & $75.3 \pm 25.6$ & $57.5 \pm 12.9$ \\
\hline \multirow[t]{2}{*}{$\geq 30$} & $61.6 \pm 25.5$ & $60.5 \pm 20.6$ & $73.5 \pm 29.2$ & $61.5 \pm 18.6$ \\
\hline & $t=-2.7 \mathrm{I}, p=0.007^{*}$ & $t=-2.100, p=0.037^{*}$ & $z=-0.10, p=0.919$ & $t=-2.20, p=0.028^{*}$ \\
\hline \multicolumn{5}{|c|}{ Education level } \\
\hline School & $55.9 \pm 22.9$ & $57.8 \pm 18.2$ & $73.9 \pm 27.8$ & $58.4 \pm 15.4$ \\
\hline \multirow[t]{2}{*}{ University } & $59.6 \pm 25.6$ & $58.8 \pm 18.2$ & $74.9 \pm 27.0$ & $60.5 \pm 16.7$ \\
\hline & $t=-1.35, p=0.177$ & $t=-0.52, p=0.604$ & $z=-0.27, p=0.784$ & $t=-1.16, p=0.245$ \\
\hline \multicolumn{5}{|c|}{ Received blood } \\
\hline Yes & $58.7 \pm 29.9$ & $56.4 \pm 20.9$ & $63.9 \pm 36.7$ & $57.2 \pm 20.8$ \\
\hline \multirow[t]{2}{*}{ No } & $57.7 \pm 23.9$ & $58.5 \pm 17.9$ & $75.3 \pm 26.4$ & $59.6 \pm 15.6$ \\
\hline & $t=0.19, p=0.847$ & $t=-0.53, p=0.598$ & $z=-1.26, p=0.209$ & $t=-0.71, p=0.479$ \\
\hline \multicolumn{5}{|c|}{ Donated blood } \\
\hline Yes & $57.3 \pm 28.6$ & $57.3 \pm 22.5$ & $76.0 \pm 31.1$ & $58.6 \pm 19.9$ \\
\hline \multirow[t]{2}{*}{ No } & $57.9 \pm 22.6$ & $58.7 \pm 16.3$ & $73.8 \pm 25.9$ & $59.8 \pm 14.5$ \\
\hline & $t=-0.165, p=0.869$ & $t=-0.493, p=0.623$ & $z=-1.49, p=0.135$ & $t=-0.524, p=0.60 \mathrm{I}$ \\
\hline
\end{tabular}

Note: Student's t-test. *Statistically significant at $p<0.05$.

Table 4 Factors associated with the perceived risks of blood transfusion

\begin{tabular}{|c|c|c|c|c|}
\hline Exposures & Dread and severity & Knowledge and control & Benefit & Total \\
\hline Outcomes & $\begin{array}{l}\text { Beta }(t) \\
p \text {-value }\end{array}$ & $\begin{array}{l}\text { Beta }(t) \\
p \text {-value }\end{array}$ & $\begin{array}{l}\text { Beta }(t) \\
p \text {-value }\end{array}$ & $\begin{array}{l}\text { Beta }(t) \\
p \text {-value }\end{array}$ \\
\hline Gender & $-0.23(-2.96)$ & $0.03(0.35)$ & $-0.13(-1.64)$ & $-0.17(-2.20)$ \\
\hline Female vs. Male & $p=0.003^{*}$ & $p=0.726$ & $p=0.103$ & $p=0.028^{*}$ \\
\hline \multirow[t]{2}{*}{ Age (years) } & $-0.09(-1.60)$ & $-0.10(-1.71)$ & $0.12(2.05)$ & $-0.06(-0.97)$ \\
\hline & $p=0.110$ & $p=0.088$ & $p=0.04 I^{*}$ & $p=0.331$ \\
\hline Education & $0.08(1.53)$ & $0.01(0.19)$ & $0.06(0.97)$ & $0.08(1.38)$ \\
\hline University vs. School & $p=0.127$ & $p=0.852$ & $p=0.333$ & $p=0.168$ \\
\hline Received blood & $-0.002(-0.04)$ & $-0.03(-0.46)$ & $-0.13(-2.19)$ & $-0.05(-0.82)$ \\
\hline Yes vs. No & $p=0.972$ & $p=0.644$ & $p=0.029 *$ & $p=0.415$ \\
\hline Donated blood & $-0.18(-2.39)$ & $-0.03(-3.42)$ & $-0.01(-0.15)$ & $-0.15(2.01)$ \\
\hline Yes vs. No & $p=0.017 *$ & $p=0.732$ & $p=0.882$ & $p=0.045^{*}$ \\
\hline
\end{tabular}

Notes: Student's t-test. *Statistically significant at $p<0.05$; Beta, coefficient of determination.

published studies. ${ }^{17,18}$ For example, a national study about the public's risk perception of blood transfusion found that $46.6 \%$ of the participants reported a moderate to high risk score for blood transfusion. ${ }^{14}$ Interestingly, male participants in our study were more likely to perceive blood transfusion as a risky procedure than females, which contradicted findings from previous studies. ${ }^{19,20}$ Studies showed that a higher percentage of perceived risk of blood transfusion is usually reported by females. ${ }^{21}$ This might be due to the fact that the current study questioned the general perception of blood transfusion, while the other cited studies focused on donation only. Generally, many factors can contribute to people's risk perception of blood transfusion, including emotional, psychological, and scientific factors. ${ }^{22}$

This study also found that older participants ( $>30$ years) were more likely to perceive blood transfusion as a risky procedure when compared with younger adults ( $<30$ years). After adjusting for all possible confounders, older participants had a significantly worse perception of blood transfusion as a beneficial procedure compared with younger participants. A one unit increase in age was associated with a 0.12 increase in the perception of risk scores reported for the benefit domain. 
The findings of this study were similar to the outcomes of other studies which found that adults' perceptions of the risks associated with blood transfusion increased with age. ${ }^{21,23,24}$ One study compared the variation in the perception of blood transfusion safety across 26 European countries. It found that women, in older age categories, who are less well educated, and lower income participants, perceived blood transfusion as a riskier procedure compared with other groups. ${ }^{23}$ The reasons why older adults have a higher risk perception of transfusion remains unclear. However, one explanation may be that age in general influences risk-taking behavior in terms of health; individuals take fewer risks with their health as they get older. ${ }^{25}$ Additionally, knowledge of health-related matters is usually higher among older adults compared with younger adults, given that they are more likely to attend screening health checkups and actively seek advice for health problems or health education to prevent illness. ${ }^{25,26}$

We would also argue here that people conceptualize health and safety risks differently, particularly when it comes to the perceptions of laypeople vs. those of experts. ${ }^{27}$ Experts (e.g., health care providers) use their educated explanatory lens as they tend to evaluate risks on the basis of probability assessments and annual fatalities, whereas laypeople tend to judge risks on the basis of risk attributes, such as catastrophic potential, threat to future generations, perceived benefits, familiarity, level of knowledge, and so forth. ${ }^{27}$ Culture can also play a role in health and safety risk perception. As Almutairi and Rodney argue, people's cultural heritage can shape the way they conceptualize health, illness, and suffering. ${ }^{28}$ It also influences how people attach meanings to things. Therefore, "risk perception" is a complex, multidimensional concept, which involves both cognitive and affective assessments of a given hazard, along with other psychological principles, worldviews, and trust. ${ }^{21,27}$

Exposure to daily life events, which shape one's perceptions, and easy access to social media, which is full of exaggerated and unreliable stories, can inflate people's risk perception. Incidences and stories of infectious diseases that can be transmitted through blood have generated feelings of dread and fear; hence, blood transfusion has been perceived to have higher risks compared with other medical procedures. ${ }^{21,22}$ Recent studies have indicated that the negative images associated with blood in general have even influenced people's perceptions of blood donation. For instance, a community-based study about public awareness of blood donation conducted in Riyadh, Saudi Arabia, showed that $14.6 \%$ of the participants did not donate blood because of the fear of infection. ${ }^{8}$ The percentage was even higher among a sample of university students in Saudi Arabia: 26\% reported that the fear of infections, such as HIV or hepatitis, was the reason they did not donate blood. ${ }^{29}$

Regardless of the fears of blood transfusion and donation among the public, our study's findings indicated that people believe in the importance and benefits of blood transfusions. Such a perception was observed in many studies, which showed that the public considered blood transfusion to be "most beneficial", even in comparison to the other nine hazards. ${ }^{16}$ The study conducted by Gader et al, which examined attitudes toward blood donation in Saudi Arabia, found that $99 \%$ of respondents showed a positive attitude toward blood donation and stressed its importance to patients. ${ }^{17}$ Interestingly, people's belief in the benefits of blood transfusion did not help lessen their fears. This can be explained by what was suggested by Adlan the word "donation" is translated into an Arabic phrase that indicates a charitable religious action. ${ }^{30}$ Saudis, in general, like to be perceived as pious ${ }^{31}$; therefore, the majority of Saudis would have a positive attitude toward donation; however, the reported perceptions of blood transfusion risks remain.

Investigating how the public perceives the risk of blood transfusions in Saudi Arabia is very important, as it can aid health care providers and policy-makers in improving the quality of care and services. Understanding patients' perspectives in this regard can help providers assist patients and their families during the decision-making process. Blood transfusion is a medical necessity, rather than an elective procedure, as blood is an irreplaceable physiological need. Therefore, health care centers should promote blood transfusion as a safe and vital procedure among the public through the media and community awareness campaigns. This will eventually improve donation rates and facilitate the process of informed consent. For instance, if a patient requires a blood transfusion, any misperception or fear of this procedure might delay securing informed consent and providing treatment. As indicated in the current study, older people tend to perceive blood transfusion as a potential hazard. Thus, healthcare centers need to focus on educating and assuring older people of the benefits and standardized safety procedures associated with blood transfusion, particularly because this age group is more prone to illness than the younger generation.

Although the strength of our study is the fact that data were collected at a national festival that attracts visitors from all over the Kingdom of Saudi Arabia, a larger sample size might confirm our findings and support their generalizability. The study results might not be generalizable to other communities with different sociocultural characteristics, such as 
the Saudi conservative community, which is pretty unique in its religious and tribally bound sociocultural characteristics. However, our findings can be compared to those from similar settings, in particular, communities that might have reservations about blood transfusion. Another study is recommended to further investigate the perception of blood transfusion among those who have not donated or received blood as they had a poorer perception in this study. These people might have gained this misconception based on a family member's or a friend's bad experience, which might make them wary of donating or receiving blood in the future.

\section{Conclusion}

People often judge blood transfusion as a risky procedure based on what they think they know, rather than what they actually know. This is related to judgments of trustworthiness. An increase in health-related knowledge may translate into increased awareness of both the benefits and risks of different health interventions, such as blood transfusion. However, knowledge regarding blood safety does not necessarily reduce risk perception. In fact, it could be argued that risk perception may be elevated, even when the risk itself is acknowledged. In general, Saudis are expected to report a poor perception of blood transfusion. Saudi males are more likely to dread blood transfusion as a high-risk procedure with potentially severe consequences compared with Saudi females. Older Saudis will probably experience a more negative perception of the benefits of blood transfusion compared with younger Saudis. Previous recipients of blood will likely have a better perception of the benefits of blood transfusion than those who have not received blood, while previous donors will have a better perception of blood transfusion as a relatively safe procedure than nondonors.

\section{Acknowledgment}

The authors would like to thank King Abdullah International Medical Research Center, Riyadh, Saudi Arabia for funding this study. This research was presented only as a poster at national research forum in Saudi Arabia on December 2017.

\section{Author contributions}

AFA and AAA conceptualized and designed the study. $\mathrm{MN}$ and OAA undertook and supervised the recruitment of patients and managed the data. MS provided statistical advice on study design and analyzed the data. All authors drafted the manuscript and contributed substantially to its revision as submitted, and agree to be accountable for all aspects of the work.

\section{Disclosure}

The authors report no conflicts of interest in this work.

\section{References}

1. Al-Drees AM. Attitude, belief and knowledge about blood donation and transfusion in Saudi population. PakJ Med Sci. 2008;24(1):74.

2. Du R, Ho B, Ding JL. Rapid reprogramming of haemoglobin structurefunction exposes multiple dual-antimicrobial potencies. EMBO J. 2010;29(3):632-642.

3. Chen J-Y, Scerbo M, Kramer G. A review of blood substitutes: examining the history, clinical trial results, and ethics of hemoglobin-based oxygen carriers. Clinics (Sao Paulo).2009;64(8):803-813.

4. Moore EE, Johnson JL, Cheng AM, Masuno T, Banerjee A. Insights from studies of blood substitutes in trauma. Shock. 2005;24(3):197-205.

5. Spahn D. Blood substitutes Artificial oxygen carriers: perfluorocarbon emulsions. Crit Care. 1999;3(5):R93.

6. Safizadeh H, Pourdamghan N, Mohamadi B. University students awareness and attitude towards blood donation in Kerman City. Iran J Blood Cancer. 2009;1(3):107-110.

7. World Health Organization. Towards $100 \%$ Voluntary Blood Donation: A Global Framework for Action. 2010.

8. Abolfotouh MA, Al-Assiri MH, Al-Omani M, Al Johar A, Al Hakbani A, Alaskar AS. Public awareness of blood donation in Central Saudi Arabia. Int J Gen Med. 2014;7:401.

9. Dubey A, Sonker A, Chaurasia R, Chaudhary R. Knowledge, attitude and beliefs of people in North India regarding blood donation. Blood Transfus. 2014;12(Suppl 1):s21.

10. Olaiya M, Alakija W, Ajala A, Olatunji R. Knowledge, attitudes, beliefs and motivations towards blood donations among blood donors in Lagos, Nigeria. Transfus Med. 2004;14(1):13-17.

11. Uma S, Arun R, Arumugam P. The knowledge, attitude and practice towards blood donation among voluntary blood donors in Chennai, India. J Clin Diagn Res. 2013;7(6):1043-1046.

12. Zaller N, Nelson KE, Ness P, Wen G, Bai X, Shan H. Knowledge, attitude and practice survey regarding blood donation in a Northwestern Chinese city. Transfus Med. 2005;15(4):277-286.

13. World Health Organization. Screening Donated Blood for TransfusionTransmissible Infections: Recommendations. World Health Organization; 2010.

14. Finucane M, Slovic P, Mertz C. Public perception of the risk of blood transfusion. Transfusion. 2000;40(8):1017-1022.

15. Rahman M, Sajani T. Recipients perception of blood transfusion risk in some selected tertiary care hospitals. AKMMC Journal. 2014;5(2):30-33.

16. Lee D, Mehta M, James P. Differences in the perception of blood transfusion risk between laypeople and physicians. Transfusion. 2003;43(6):772-778.

17. Gader AGMA, Osman AMA, Al Gahtani FH, Farghali MN, Ramadan AH, Al-Momen AKM. Attitude to blood donation in Saudi Arabia. Asian J Transfus Sci. 2011;5(2):121.

18. Whang DH, Um TH, Ha M. [Perception of the risks of blood transfusion in Koreans.] Korean J Lab Med. 2009;29(6):570-577. Korean

19. Vetter TR, Adhami LF, Porterfield Jr JR, Marques MB. Perceptions about blood transfusion: a survey of surgical patients and their anesthesiologists and surgeons. Anesth Analg. 2014;118(6):1301-1308.

20. Masser BM, White KM, Hamilton K, McKimmie BM. An examination of the predictors of blood donors' intentions to donate during two phases of an avian influenza outbreak. Transfusion. 2011;51(3):548-557.

21. Lee D. Perception of blood transfusion risk. Transfus Med Rev. 2006;20(2):141-148.

22. Ngo LT, Bruhn R, Custer B. Risk perception and its role in attitudes toward blood transfusion: a qualitative systematic review. Transfus Med Rev. 2013;27(2):119-128.

23. Merz EM, Zijlstra B, Kort W. Perceived blood transfusion safety: a cross-European comparison. Vox Sang. 2015;110(3):258-265. 
24. Moxey A, O'connell D, Treloar C, Han P, Henry D. Blood transfusion and autologous donation: a survey of post-surgical patients, interest group members and the public. Transfus Med. 2005;15(1):19-32.

25. Rolison JJ, Hanoch Y, Wood S, Liu P-J. Risk-taking differences across the adult life span: a question of age and domain. J Gerontol B Psychol Sci Soc Sci. 2014;59(6):870-880.

26. Deeks A, Lombard C, Michelmore J, Teede H. The effects of gender and age on health related behaviors. BMC Public Health. 2009;9(1):213.

27. Slovic P. The Perception of Risk. Risk, Society, and Policy Series. London: Earthscan; 2000.
28. Almutairi A, Rodney P. Critical cultural competence for culturally diverse workforces: toward equitable and peaceful health care. ANS Adv Nurs Sci. 2013;36(4):363.

29. Baig M, Habib H, Haji AH, Alsharief FT, Noor AM, Makki RG. Knowledge, misconceptions and motivations towards blood donation among university students in KSA. Pak J Med Sci. 2013;29(6):1295.

30. Adlan AAA. The Biomedical Ethics of Donating Blood for Molecular and Genetics Research in Saudi Arabia. University of Birmingham; 2015.

31. Adlan AA. Informed Consent in Saudi Arabia. Legal and Forensic Medicine. Berlin: Springer; 2013:893-907.
Journal of Blood Medicine

\section{Publish your work in this journal}

The Journal of Blood Medicine is an international, peer-reviewed, open access, online journal publishing laboratory, experimental and clinical aspects of all aspect pertaining to blood based medicine including but not limited to: Transfusion Medicine; Blood collection, Donor issues, Transmittable diseases, and Blood banking logistics; Immunohematology; Artificial and alternative
Dovepress

blood based therapeutics; Hematology; Biotechnology/nanotechnology of blood related medicine; Legal aspects of blood medicine; Historical perspectives. The manuscript management system is completely online and includes a very quick and fair peer-review system. Visit http://www.dovepress.com/ testimonials.php to read real quotes from published authors. 